\title{
Bestimmung von Glucose und freien Fettsäuren im Serum nach Gabe von Alkohol und Glycin
}

\author{
Von E. Liebhardt und J. G. GostomzyK \\ Aus dem Institut fïr gericbtliclse Medizin und Versicberungsmedizin der Universität Freiburg i. Br. \\ (Direktor: Prof. Dr. W. Spann)
}

(Eingegangen am 26. Februar 1968)

Bei gesunden männlichen Versuchspersonen wurde während eines Alkohol-Trinkversuches (0,9 g Alkohol/kg KG) die Wirkung von oral zum Alkohol verabreichtem Glycin $(0,3 \mathrm{~g} / \mathrm{kg} \mathrm{KG})$ auf die Blutalkoholkonzentrationen sowie die Konzentrationen der unveresterten Fettsäuren und der Glucose im Serum über 7 Stdn. untersucht. Dabei verändert Glycin den Verlauf der BlutalkoholkonzentrationsKurven nicht signifikant. Die freien Fettsäuren zeigen in der mit Glycin behandelten Gruppe und in der Kontrollgruppe, die lediglich Alkohol erhalten hatte, einen gleich großen Anstieg. Der nach 7 Stdn. erreichte Wert liegt etwas unter dem morgendlichen Nüchternwert $(445 \pm 170 \mu \mathrm{Val} / I)$ eines vergleichbaren Kollektivs. In der glycinbehandelten Gruppe war 150 bzw. 270 Min. nach Trinkende die Glucosekonzentration im Serum gegenüber dem Ausgangswert erhöht.

\section{The determination of glucose and free fatty acids in serum after the administration of alcokol and glycine}

The concentration of blood alcohol and free fatty acids, and of serum glucose was studied in healthy adult human males over a period of seven hours following the consumption of alcohol $(0.9 \mathrm{~g} / \mathrm{kg}$ body weight), or of alcohol plus glycine $(0.3 \mathrm{~g} / \mathrm{kg})$. The course of the blood alcohol concentration was not altered significantly by glycine. The free fatty acids increased by the same amount in both groups, and then decreased, so that after seven hours their concentration was somewhat lower than the resting morning value $(445 \pm 170 \mu \mathrm{eq} / 1)$ of a comparable control group. 150-270 min. after drinking alcohol, the serum glucose concentration of the glycine-treated group was higher than the starting value.

Die Blutalkoholkonzentration steigt im Trinkversuch langsamer an, wenn mit dem Alkohol die Aminosäure Glycin verabreicht wird $(1,2)$. Als Ursache werden wegen der längeren Verweildauer des Alkohols im Magen eine verzögerte Resorption (1) oder die chemische Bindung von Äthanol durch die Aminosäure in Anspruch genommen $(2,3)$. Ungeklärt ist die Frage, ob die Gabe von Glycin in einer Abbauphase des Alkohols den Energiestoffwechsel beeinflußt, denn die orale Gabe von Aminosäuren führt zu einem Anstieg der Glucagon-Konzentration im Plasma (4).

Sowohl Åthylalkohol als auch Glucagon sind im Fettstoffwechsel wirksam. Aus dem Alkohol wird in der Leber Acetyl-Coenzym-A gebildet, das zur Synthese von Fettsäuren herangezogen werden kann (5). Weiter wird für Alkohol eine mobilisierende Wirkung auf das Depot-Fett angenommen, das dann in der Leber angehäuft wird (6). Noch vor dem Diabetes melliturs -wird der chronische Alkoholgenuß als häufigste Ursache für die Entwicklung der Fettleber angesehen $(7,8,9)$. Die intravenöse Injektion von Glucagon ( $7 \mu \mathrm{g}$ pro $\mathrm{kg}$ Körpergewicht) führt zu einer Glykämie, die ihr Maximum nach etwa 30 Min. erreicht und zu einer Erniedrigung des Spiegels der nicht veresterten freien Fettsäuren im Plasma, der 30-90 Min. nach der Injektion nachweisbar ist (10).

Angesichts dieser Befunde schien es uns interessant, das Verhalten der wichtigsten Energielieferanten im Blut, der freien Fettsäuren und der Glucose, im Trinkversuch mit und ohne Glycin zu untersuchen.

\section{Untersuchungsgut und Methode}

Die Untersuchungen wurden an 6 männlichen Versuchspersonen (Studenten) an verschiedenen Tagen jeweils im Abstand von einer Woche durchgeführt. Die Versuchspersonen erhielten von 6.00 bis 6.30 Uhr ein normiertes leichtes. Frühstück. An Stelle einer Nüchternwert-Kontrolle des Blutalkoholspiegels wurde eine vor Beginn der Alkoholaufnahme abgegebene Harnprobe untersucht. Von 8.00 bis $8.50 \mathrm{Uhr}$ wurden $0,9 \mathrm{~g}$ Alkohol (Wodka, $32 \mathrm{Gew} \% \%$ ) pro kg Körpergewicht in 6 annähernd gleichen Portionen verabreicht. Dazu erhielt ein Teil der Versuchspersonen 0,3 g Glycin oder 0,3 g Milchzucker pro kg Körpergewicht. Die Substanzen waren mit Wasser zu einer Paste angerührt und wurden in 6 Portionen mit dem Alkohol gegeben. Zur Blutentnahme verwendeten wir Venülen ohne Zusatz.

Die Bestimmungen der freien Fettsäuren erfolgten titrimetrisch nach der Methode von DoLE in der Modifikation nach Trour und Mitarbeiter unter Verwendung von Nil-Blau-A als Indikator (11).

Die enzymatische Bestimmung der Glucose im Serum wurde nach Vorschrift des Biochemica-Farbtestes der Firma Boehringer (Mannheim) ausgeführt.

\section{Ergebnisse und Diskussion}

Die Abbildung 1 zeigt das Verhalten der Blutalkoholkonzentration während der Versuche. Wurde zum Alkohol Glycin verabreicht, so war der Anstieg der Blutalkoholkonzentration verzögert. Bei der ersten Blutentnahme, $10 \mathrm{Min}$. nach Trinkende, lag die Blutalkoholkonzentration in der Glycin-Gruppe im Mittel um $0,44 \%$ unter der mittleren Blutalkoholkonzentration der Kontrollgruppe, wobei die Werte beider Gruppen mit einer Irrtumswahrscheinlichkeit $\alpha<2 \%$ $(t=4,48, f=4)$ verschieden sind $(t=$ Test $)$. Wurde an Stelle von Glycin 0,3 g Milchzucker pro kg Körpergewicht verabreicht, so ergab der statistische Vergleich der mittleren 9.00 Uhr-Werte zwischen der Glycinund der Milchzucker-Gruppe einen Unterschied von $0,10 \%$, der statistisch nicht signifikant ist $(t=1,18)$. Zwischen den Mittelwerten der Gruppe, die Milchzucker exhalten hatte und der Kontrollgruppe besteht eine Differenz von $0,28 \%$. Ein verschiedenes Verhalten beider Gruppen war statistisch nicht zu sichern $(\alpha<20 \%, t=1,86, f=4)$, da eine solche 


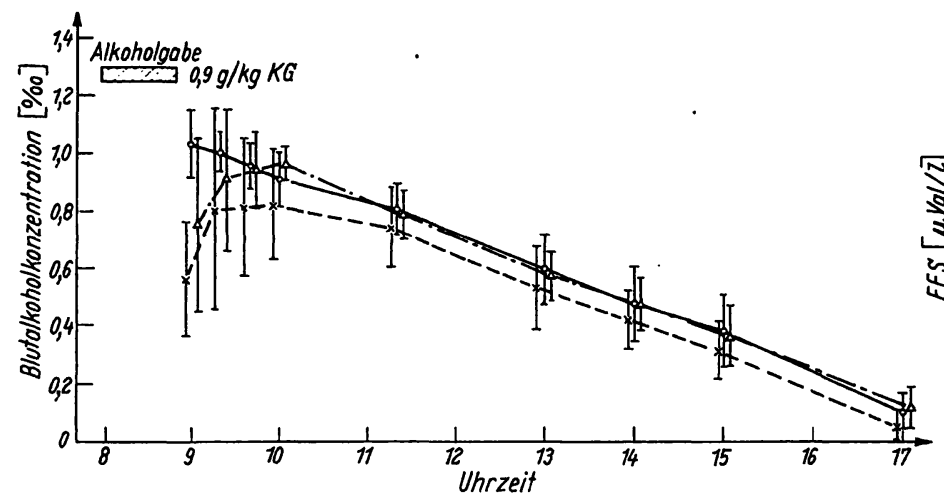

Abb. 1

Verhalten der Blutalkoholkonzentrationen nach Gabe von $0,3 \mathrm{~g}$ Glycin/kg $(x-x, n=5)$ oder $0,3 \mathrm{~g}$ Milchzucker $/ \mathrm{kg}(\Delta-\Delta, \mathrm{n}=6)$

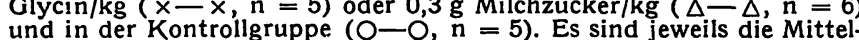
werte der Meßwerte der einzelnen Gruppen eingezeichnet. Die senkrechten Pfeile geben die einfache Streuung an

Aussage mit einer Irrtumswahrscheinlichkeit $\alpha<20 \%$ behaftet ist. $\mathrm{Zu}$ allen untersuchten Zeitpunkten später als 10 Min. nach Trinkende ergaben sich zwischen den 3 Versuchsgruppen keine statistisch signifikanten Unterschiede in den Mittelwerten der Blutalkoholkonzentration.

Die nach Glycin beobachtete Verzögerung der Alkoholresorption läßt sich auch nach Gabe von Milchzucker feststellen. Dies spricht für eine unspezifische Verzögerung der Resorption. Ähnliche Verzögerungen können durch unspezifische Nahrungsmittel ebenfalls erreicht werden (12). Ursache mag die unterschiedliche Resorptionsgeschwindigkeit für Alkohol in verschiedenen Abschnitten des Verdauungstraktes sein, wie sie an zeitweise isolierten Darmabschnitten im Tierexperiment nachgewiesen wurde (13). Als spezifisches Mittel zur Steigerung der Alkoholtoleranz in bezug auf die Blutalkoholkonzentration erscheint uns Glycin deshalb ungeeignet (14).

In der Abbildung 2 ist das Verhalten der freien Fettsäuren im Serum während der Trinkversuche dargestellt. Es zeigt sich, daß die Konzentration der freien Fettsäuren in beiden Kollektiven während der Untersuchung etwa gleichartig ansteigt. Sechs Stunden nach Trinkende wird ein Wert erreicht, der etwas unterhalb des morgendlichen Nüchternwertes von $445 \pm 170$ $\mu \mathrm{Val} / l, \mathrm{n}=23$, eines vergleichbaren Kollektivs liegt.

Nach Nahrungsaufnahme, nach Infusion von Glucose oder nach Mobilisierung von Glucose durch Injektion von Insulin oder Glucagon sinkt die Konzentration der freien Fettsäuren im Plasma und steigt nach Abfall der Glucose-Konzentration wieder an (15). Dieser Anstieg bedeutet eine Bereitstellung von Fett als EnergieQuelle, wenn nicht genügend Glucose zur Verbrennung zur Verfügung steht. Die Mobilisierung von Fettsäuren erfolgt, wie ersichtlich (Abb. 2) auch bei Anwesenheit von Äthylalkohol im Blut und bleibt weiterhin durch Gabe von Glycin unbeeinflußt.

Das in Abbildung 3 dargestellte Verhalten der Glucose-Konzentrationen im Serum während der Untersuchungen läßt erkennen, daß die Gruppe, die zum Alkohol Glycin in 6 gleich großen Portionen einnahm,

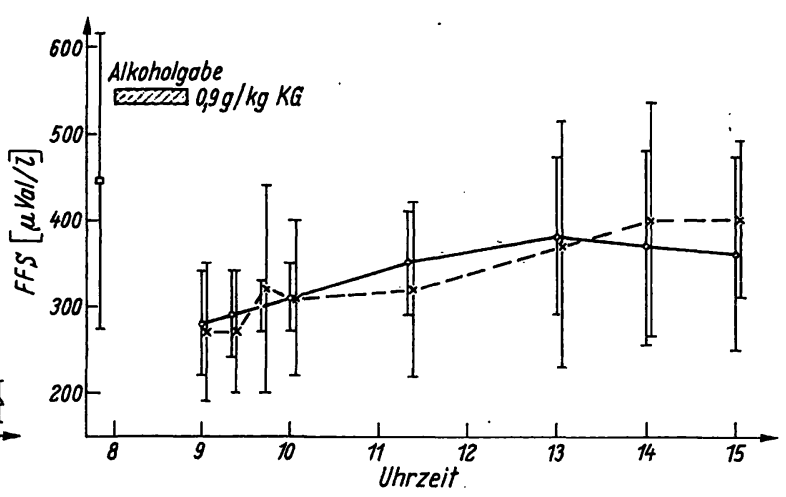

Abb. 2

Anstieg der unveresterten freien Fettsäuren (FFS) im Serum während eines Trinkversuches mit $(x-x, \mathrm{n}=5)$ und ohne $(0-0, \mathrm{n}=5)$ eines Trinkversuches mit $(x-\times, n=5)$ und ohne $(0-O, n=5)$
Zugabe von $0,3 \mathrm{~g}$ Glycin $/ \mathrm{kg}$. Angegeben sind die Mittelwerte und die einfache Streuung. $\square=$ Nüchternwert $(n=23)$

150 bzw. $270 \mathrm{Min}$. nach Trinkende ein gegenüber dem Ausgangswert (10 Min. nach Trinkende) erhöhten Glucose-Spiegel aufweist $(\alpha<20 \%, \mathrm{t}=1,66$ bzw. $1,77, f=4)$. Werden in die statistische Auswertung weitere Versuchsergebnisse einbezogen, in

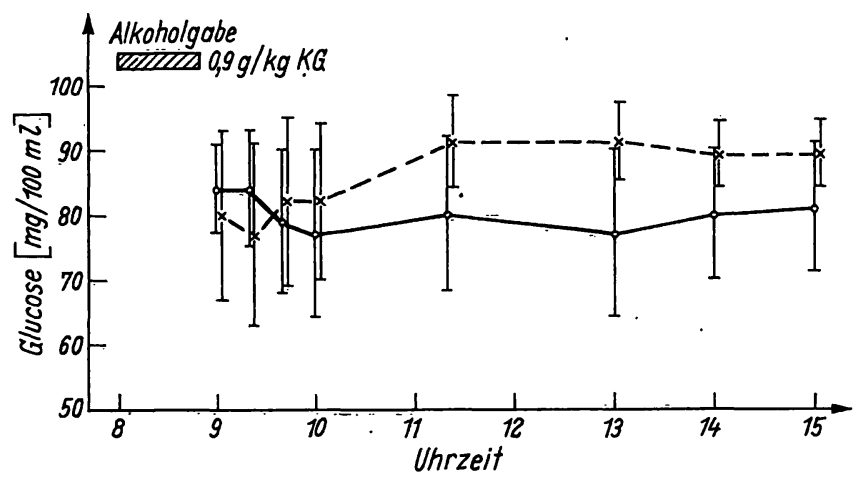

Abb. 3

Verhalten der Glucose-Konzentrationen (Mittelwerte und einfache Streuung) im Serum während des Trinkversuches. $O-O$ ohne

denen bei sonst gleicher Versuchsanordnung lediglich die gleiche Menge Glycin als einmalige Dosis zu Beginn oder am Ende der Alkoholaufnahme verabreicht wurden und dem Glycin $10 \mathrm{mg}$ Fluorescein-Na (Fa. Riedel-de Haën AG) pro kg Körpergewicht zugesetzt waren, so ist gegenüber dem $9.00 \mathrm{Uhr}$-Wert $(80 \pm 9 \mathrm{mg} / 100 \mathrm{ml})$ der um 11.20 Uhr festgestellte Wert $(93 \pm 8 \mathrm{mg} / 100 \mathrm{~m} /$ ) mit einer Irrtumswahrscheinlichkeit $\alpha<1 \% \quad(t=3,5, f=10)$ verschieden. Für 13.00 Uhr ergibt sich ein Mittelwert von $90 \pm 8 \mathrm{mg} /$ $100 \mathrm{ml}$, der mit einer Irrtumswahrscheinlichkeit $\alpha<3 \%$ $(t=2,7, f=10)$ gegenüber dem $9.00 \mathrm{Uhr}$-Wert verschieden ist.

Der 5 Stdn. nach Nahrungsaufnahme und 150-200 Min. - nach oraler Gabe des Glycins festgestellte Anstieg der Glucose-Konzentration im Serum ist sehr wahrscheinlich als Effekt einer Glycin-induzierten Ausschüttung von Glucagon zu deuten. Der beobachtete lange zeitliche Abstand zwischen Glycin-Gabe und GlucoseAnstieg ist, verglichen mit der rascheren Wirkung einer intravenösen Glucagon-Gabe, durch die. Re- 
sorptionszeit des Glycins zu erklären. Die GlucoseMobilisation ist bei intravenöser Verabreichung von Aminosäuren stärker als bei oraler Gabe (4). Der Blutzuckeranstieg als Ausdruck einer Glukoneogenese nach Verabreichung der glukoplastischen Aminosäure Glycin ist jedoch durch die Versuchsergebnisse nicht ausgeschlossen.

Die beobachtete Glykämie nach gleichzeitiger Aufnahme von Alkohol und Aminosäuren und die in allen 3 Versuchsgruppen von $30 \mathrm{Min}$. nach Trinkende an praktisch gleich hohen Blutalkoholkonzentrationen sprechen gegen eine etwaige chemische Bindung zwischen Aminosäure und Alkohol $(2,3)$.

Die nach Glycin-Gabe beobachtete Glykämie senkt nicht den Spiegel der freien Fettsäuren im Plasma und vermindert somit nicht das Angebot von freien Fettsäuren an die Leber. Für eine Schutzwirkung der Aminosäure Glycin bei der Entwicklung einer alkoholinduzierten Fettleber während der Phase des $\mathrm{Al}$ koholabbaues ergeben sich weder aus dem Verhalten der Energielieferanten im Plasma noch aus der Höhe der Blutalkoholkonzentration irgendwelche Anhaltspunkte.

\title{
Literatur
}

1. Haggard, H. W. und L. A. Greenberg, J. Pharmacol. Exper. Therap. Baltimore 68, 482 (1940). - 2. WIDMark, E., Biochem. Z. 270, 297 (1934). - 3. PRoKop, L., Zschr. ärztl. Fortbild. 52, 407 (1963). - 4. Assan, R., zit. nach einem Referat über die Pariser Diabetes-Jahrestagung 1967 „Glucagon und Kohlenhydratstoffwechsel" in Aktuelle Medizin, 29, Beil. zur Münch. Med. Wschr. 109 (1967). - 5. Popper, H., Acta hepato-splenol. (Stuttg.), 8, 279 (1961). - 6. AMmoN, H. P. T. und C. J: EsTLER, Klin. Wschr. 44, 650 (1966). - 7. Frscher, H., Münch. Med. Wschr. 45, 2353 (1967). - 8. Avenarius, H. J. und W. Eger,
Mat. Med. Nordmark 19, 283 (1967). - 9. Martini, G. A. und W. Dölle, Dtsch. med. Wschr. 90, 793 (1965). - 10. Brech, W. J. und E. S. Gordon, Klin. Wschr. 45, 906 (1967). - 11. Zöllner, N. und D. Eberhagen, Untersuchungen und Bestimmungen der Lipoide im Blut, S. 339, Springer Berlin-HeidelbergNew York (1965). - 12. Elbel, H., Blutalkohol, 2. Aufl., S. 68 Thieme, Stuttgart (1956). - 13. Elmslie, R. G. und N. HarveY, Quart. J. Alcohol 28, 555 (1967). - 14. Diese Aussage wird durch weitere bisher unveröffentlichte Befunde, die am hiesigen Institut erhoben wurden, gestützt.
Dr. J. G. Gostomzyk 78 Freiburg i. Br. Albertstr. 9

\section{Dünnschichtchromatographische Untersuchungen der Faeces-Lipide Methodik und Untersuchungsbefunde bei gesunden Probanden}

\author{
Von W. ERB und E. BöHLE \\ Aus der I. Medizinischen Universitätsklinik Frankfurt|Main (Direktor: Prof. Dr. W. Siede) \\ (Eingegangen am 6. März 1968)
}

Herrn Prof. Dr. W. Siede zum 60. Geburtstag gewidmet

Es wird eine Methode zur dünnschichtchromatographischen Trennung und quantitativen Analyse der Faeceslipide beschrieben, die sich für Routinezwecke eignet. Die Untersuchungsbefunde von 18 gesunden Probanden werden mitgeteilt und mit den bisher bekannten Daten verglichen.

The investigation of faecal lipids by thin layer chromatography. Methodology, and the results from normal probands

A method is described for the separation and quantitative determination of faecal lipids by thin layer chromatography, which is suitable for routine work. The results from 18 healthy probands are reported and compared with existing data.

Die Einführung der Dünnschichtchromatographie durch Stahr (1-4) hat die Analyse von Lipidgemischen erheblich vereinfacht. Mit Hilfe dieser Methode lassen sich nicht nur Gruppentrennungen der verschiedenen Hauptlipidfraktionen, sondern auch weitergehende Differenzierungen (z. B. Auftrennung der Phospholipide, Sterinester und Fettsäuren) durchführen.
In der vorliegenden Arbeit soll über methodische Einzelheiten dünnschichtchromatographischer - Analysen von phospholipidfreien Lipidextrakten menschlicher Faeces sowie über die Zusammensetzung des Stuhlfettes gesunder Probanden berichtet werden. Systematische Untersuchungen hierüber standen bisher noch aus. 